Kök gelişimi

tamamlanmamış üst

keser dişin biodentine

ile apeksifikasyonu:

Olgu sunumu

\section{Apexification of the upper incisor tooth with incomplete root development using biodentine: A case report}

\author{
Dr. Öğr. Üyesi Hüseyin Gündüz \\ Van Yüzüncü Yıl Üniversitesi, Diş Hekimliği Fakültesi, \\ Endodonti A.D., Van \\ Orcid ID: 0000-0003-1580-3159
}

\section{Dr. Öğr. Üyesi Esin Özlek}

Van Yüzüncü Yıl Üniversitesi, Diş Hekimliği Fakültesi, Endodonti A.D., Van

Orcid ID: 0000-0003-1446-284X

Geliş tarihi: 27 Aralık 2020

Kabul tarihi: 29 Eylül 2021

doi: 10.5505/yeditepe.2022.44365

\section{Yazışma adresi:}

Hüseyin Gündüz

Van Yüzüncü Yıl Üniversitesi, Diş Hekimliği Fakülte-

si, Endodonti A.D., Bardakçı Mah. Zeve Kampüsü

Tuşba/Van

Tel: +905413523162

E-posta: huseyingunduz@yyu.edu.tr

Vaka raporu özetinin yayınlama yeri: 26. İzmir Diş

Hekimleri Odası Uluslararası Kongre ve Sergisi Tarihi:

$08 / 11 / 2020$
ÖZET

Bu olgu sunumunun amacı, açık apeksli üst santral dişe Biodentine ile uygulanan apeksifikasyon tedavisinin sonuçlarını bildirmektir. Üst ön bölgesinde travma hikayesi olan 9 yaşındaki hasta ağrı şikayetiyle başvurmuştur. Radyolojik incelemede sol üst santral dişin kök gelişiminin tamamlanmadığı ve ilgili bölgede radyolüsent alan olduğu tespit edilmiştir. Apikal tıkaç oluşmadığından dolayı Biodentine ile apeksifikasyon tedavisi yapılmasına karar verilmiştir. Kök kanal tedavisine başlanmış ve kök kanallarına kalsiyum hidroksit yerleştirilmiştir. 14 gün sonra, üretici firma talimatları doğrultusunda Biodentine, kök kanalına yerleştirilmiş ve apikalde 5 mm'lik bir tıkaç oluşturulmuştur. Biodentine sertleştikten sonra, kanalın koronal kısmı devamlı Isı ile vertikal kompaksiyon tekniği doldurulmuştur. Diş A2 kompozitle (Solare X, Tokyo, Japonya) restore edilmiştir. 3, 6 ve 12 aylık takiplerinde klinik semptomların kaybolduğu ve periapikal lezyonda radyografik olarak iyileşme olduğu tespit edilmiştir. Biodentine sahip olduğu üstün fiziksel ve biyolojik özellikler sayesinde kök gelişimi tamamlanmamış dişlerin apeksifikasyonunda başarılı sonuçlar göstermiştir.

Anahtar kelimeler: Apeksifikasyon, diş kökü, trikalsiyum silikat.

\section{SUMMARY}

The aim of this case report is to report the results of apexification treatment with Biodentine on the upper central tooth with open apex. A 9-year-old patient with a history of upper anterior trauma presented with pain. In the radiological examination, it was determined that the root development of the left upper central tooth was not accomplished and there was a radiolucent area in the related region. Since there was no apical plug, it was decided to perform Biodentine apexification treatment. Root canal treatment was began and calcium hydroxide was placed into the root canals. 14 days later, $\mathrm{Bi}$ odentine was carried into the canal in accordance with the manufacturer's instructions and a $5 \mathrm{~mm}$ plug was formed at the apical. After Biodentine setting, coronal part of the canal was filled using continuous wave warm vertical compaction technique. The tooth has been restored with A2 composite (Solare X, Tokyo, Japan). At 3, 6, and 12 months of follow-up, no clinical symptom was found and the periapical lesion was reduced. Due to its superior physical and biological properties, Biodentine has shown successful results in the apexification of teeth whose root development is incomplete.

Key words: Apexification, tooth apex, tricalcium silicate. Gíiş

Travma, çürük veya diğer pulpal patolojilere bağlı pulpasında nekroz gelişen immatür dişlerde, dentin oluşumu durmakta ve kök gelişimi tamamlanamamaktadır. Bunun sonucunda da kök kanalı geniş, ince ve kırılgan duvarlara sahip olmakta ve kök apeksi açık kalmaktadır. Bu kök kanal yapısı kök kanal enstrümantasyonunu zorlaştırmakta ve yeterli bir apikal stop elde edilmesini engellemektedir. Bu gibi durumlarda kök kanal dolgu maddesinin kondensasyonuna izin vermek ve 
apikal sızdırmazlığı arttırmak için yapay bir apikal bariyer oluşturmak veya apikal açıklığın kalsifiye doku ile kapatılmasını indüklemek gerekmektedir. Apeksifikasyon "açık apeksli dişlerin kök ucunda kalsifye bariyer oluşturulması ya da nekrotik pulpalı, kök gelişimini tamamlamamış dişlerde apikal oluşumun devamının sağlanması" olarak tanımlamıştır. ${ }^{2}$

Kök ucu bariyeri oluşumunu indüklemek için farklı malzemeler kullanılarak birçok prosedür önerilmiş olsa da kalsiyum hidroksit en çok kullanılan ve kabul gören prosedür olarak bilinmektedir. ${ }^{3}$ Bu prosedür ile yapılan çalışmalara bakıldığında etkili bir tedavi olmasına karşın kalsiyum hidroksit kullanımının birçok dezavantajı bulunmaktadır. Bu dezavantajlar, apikal bir bariyer oluşturmak için uzun zaman gerektirmesi, çoklu seans intiyacı, hasta uyumu, geçici restorasyon kaybından dolayı tekrarlayan enfeksiyon, dişin kırılmaya yatkınlığı ve oluşan kalsifiye bariyerin gözenekli ve düzensiz olmasıdır. ${ }^{4}$

Kalsiyum hidroksit apeksifikasyonu ile bu dezavantajlar göz önüne alındığında, apikal tıkaç yönteminin kullanımının bu gibi durumlar için uygun bir alternatif tedavi yöntemi olacağı bildirilmiştir. Bu yöntemde, periapikal bölgede kalsifiye bir barikat oluşumunu indüklemek için kök ucunun açık alanına kompakt bir bariyer yerleştirilir. Bu bariyerin sertleşmesinden sonra kanalın geri kalan kısmı gütaperka ile doldurulur. Bu tekniğin avantajları, daha kısa tedavi süresi ve iyi bir apikal tıkama oluşturmasıdır. ${ }^{5}$ Son yıllarda bu amaç için trikalsiyum silikat içerikli mineral trioksit agregat (MTA) ve Biodentine gibi biyoaktif ve biyouyumlu maddeler kullanılmaktadır. ${ }^{4-6}$

MTA, biyouyumluluk, rejeneratif kapasite, üstün sızdırmazlık ve antibakteriyel özellikleri nedeniyle tek seans apeksifikasyon için yaygın olarak kullanılmaktadır. ${ }^{7}$ Bununla birlikte, MTA'nın, uzun sertleşme zamanı, kullanımının zor olması, basınca karşı düşük direnç, düşük akışkanlık, sertleşme öncesi sınırlı direnç, diş yapısının renklenme olasılığı, yüksek maliyet, arsenik varlığı ve salınımı gibi bazı dezavantajları bildirilmiştir. ${ }^{8}$ Bu dezavantajlar nedeniyle yeterli biyolojik ve mekanik özelliklere sahip daha ideal restoratif materyal arayışına girilmiştir. Son zamanlarda, MTA'nın özelliklerinin ve klinik uygulamalarının olumsuz yönlerini ortadan kaldırmak amacıyla, daha üstün fiziksel ve biyolojik özelliklere sahip yeni bir kalsiyum silikat bazlı malzeme olan Biodentine (Septodont, Saint-Maur-desFossés, Fransa) tanıtıımıştır.

Biodentine, trikalsiyum silikat, kalsiyum karbonat, zirkonyum oksit, dikalsiyum silikat, kalsiyum oksit içeren toz ve sertleşmeyi hızlandırmak için kalsiyum klorür, plastikleştirici madde olarak modifiye edilmiş polikarboksilat içeren sıvı kısımdan oluşmaktadır. ${ }^{9}$ Toz, bir amalgamatör ile 30 saniye sıvı ile karıştırılmaktadır. Biodentine, mükemmel viskozitesi ve yaklaşık 12 dakika olan kısa sertleşme süresi nedeniyle yeterli kullanım özelliklerine sahiptir. Bu ma- teryal koronal restorasyonlarda, pulpa kuafajlarında, kaide materyali olarak, pulpotomide, kök perforasyonlarının tamirinde, internal ve eksternal kök rezorpsiyonlarında, apeksifikasyon tedavisinde apikal bariyerlerin oluşumunda, rejeneratif tedavilerde ve endodontik cerrahide retrograd dolgu mateddesi olarak kullanılabilmektedir. ${ }^{10}$

Bu vaka raporunun amacl, apikal gelişimi tamamlanmamış ve periapikal lezyonlu daimi üst santral dişe uygulanan Biodentine ile apeksifikasyon tedavisinin sonuçlarını sunmaktır.

\section{OLGU SUNUMU}

Üst ön bölgesinde travma hikayesi olan 9 yaşındaki kız hasta üst ön bölgesinde ağrı şikayetiyle kliniğimize başvurmuştur. Hastanın ağız içi muayenesinde dişte mobilite, kırık veya renklenme izlenmemiş, sol üst ön bölgede fistül varlığı gözlemlenmiştir. Radyolojik incelemede sol üst santral dişin apikal gelişiminin tamamlanmadığı ve ilgili bölgede düzensiz sınırlı radyolüsent alan olduğu tespit edilmiştir (Şekil 1).

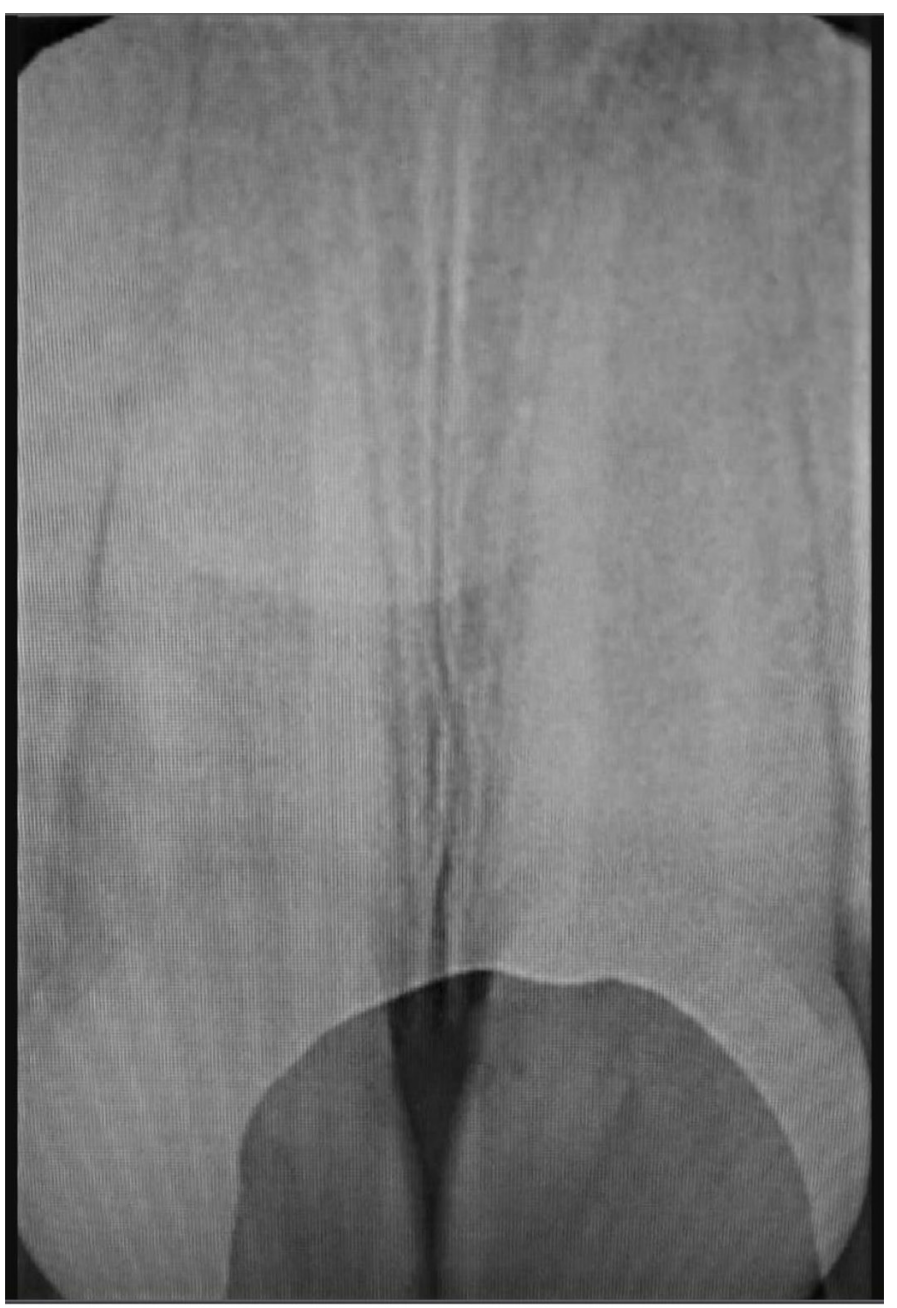

Şekil 1. İşlem öncesi periapikal radyograf

Elektrikli pulpa testi ve soğuk testiyle uygulanan vitalite uygulamasına negatif cevap alınmıştır. Perküsyon ve palpasyonda ağrılı cevap gözlenmiştir. Klinik ve radyolojik muayeneler sonucunda dişe kronik apikal periodontitis tanısı konulmuştur. Geleneksel kök kanal doldurma yöntemleri kullanılarak açık apeksli dişlerde apikal bölgede 
sızdırmaz şekilde tıkama sağlanamayacağından, hastaya Biodentine ile apeksifikasyon tedavisi yapılmasına karar verilmiştir. Hastaya ve ailesine apeksifikasyon tedavisi hakkında bilgi verilmiş, hasta velisinden 'bilgilendirilmiş olur' formu alınmıştır. Hastadan veya gereği durumunda yasal temsilcisinden izin alınmıştır. Rubber dam izolasyonu altında endodontik giriş kavitesinin açılmasının ardından çalışma boyu apikal açıklık nedeniyle 80 no'lu K tipi eğe (Mani Inc, Tochigi, Japonya) radyografik olarak belirlenmiştir. Kök kanalından enfekte pulpa ve dentin dokusu artıkları 80 no'lu H tipi (Mani Inc, Tochigi, Japonya) kanal eğeleri ile uzaklaştırılmıştır. Şekillendirme ve genişletme işlemi sırasında her eğe değişiminde $2 \mathrm{ml} \% 5,25$ 'lik NaOCI (Microvem, İstanbul, Türkiye) solüsyonu ve daha sonra distile su ile yandan perfore NaviTip irrigayon iğnesi (30G; Ultradent Products Inc, Utah, ABD) kullanılarak yıkanmıştır. Kâğıt konlarla (Dentsply Maillefer, Ballaigues, İsviçre) kurutulan kök kanalına kalsiyum hidroksit (Kalsin, Aktu Tic. İzmir, Türkiye) yerleştirilmiş ve giriş kavitesi geçici dolgu maddesi (Cavit G, ESPE, Seefeld, Almanya) ile kapatılmıştır. Hastaya 14 gün sonrasına randevu verilmiştir. İkinci seansta geçici dolgu kaldırılmış ve kalsiyum hidroksit kök kanalından 80 no'lu H tipi (Mani Inc, Tochigi, Japonya) kanal eğeleri ile uzaklaştırılmıştır. Final irrigasyon işleminde sırasıyla 5 ml \%17 EDTA (İmicryl, Konya, Türkiye), \%5,25 $\mathrm{NaOCl}$ ve $5 \mathrm{ml}$ distile su kullanılmıştır. Kök kanalı kâğıt konlarla kurutulmuş ve üretici firma önerileri doğrultusunda Biodentine amalgamatörde karıştırılmıştır. Bir amalgam taşıyıcı yardımı ile kanala yerleştirilmiş ve plugger kullanılarak apikalde 5 mm'lik bir tıkaç oluşturulana kadar işlem radyografik olarak kontrol edilerek tekrarlanmıştır. Uygulamadan 12 dakika sonra Biodentine'nin tam olarak sertleşip sertleşmediği plugger ile kontrol edildikten sonra, koronal kısım System B obturasyon (SybronEndo, Orange, ABD) sistemi kullanılarak akışkan guta perka ve AH Plus kanal patı (Dentsply DeTrey, Konstanz, Almanya) ile doldurulmuştur (Şekil 2).

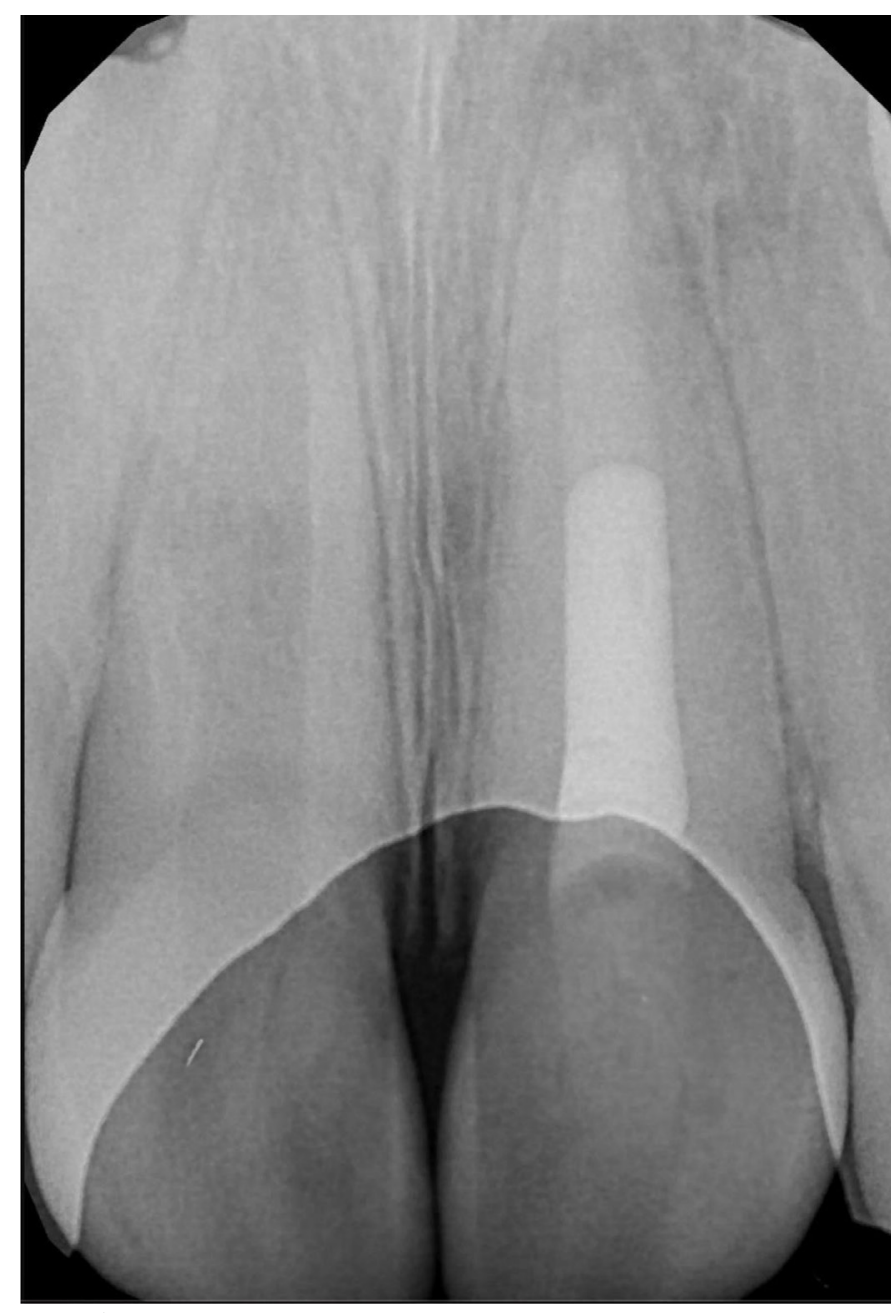

Şekil 2. İşlem sonrası periapikal radyograf.

Diş A2 kompozitle (Solare X, Tokyo, Japonya) restore edilmiştir. 3, 6 ve 12 aylık klinik ve radyografik takiplerde semptomların kaybolduğu ve periapikal lezyonda radyografik olarak iyileşme olduğu gözlemlenmiştir (Şekil 3).

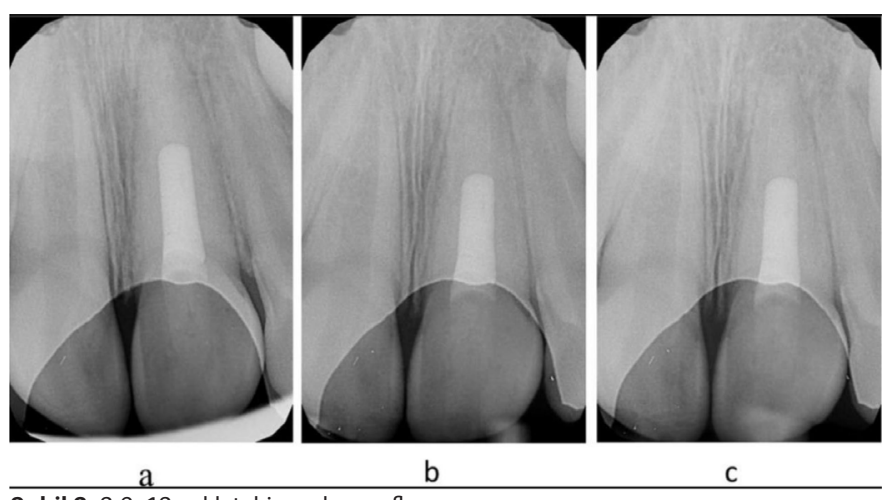

Şekil 3. 3,6, 12 aylık takip radyografları.

\section{TARTIŞMA}

Açık apeksli dişlerin kök kanal tedavisinde sıklıkla zorluklarla karşılaşılmaktadır. Apikal bölgede sert doku bariyerinin bulunmaması, taşkın kök kanal dolumuna neden olmakta hassasiyet, ağrı ve enfeksiyon gibi bulguların görülmesine yol açmaktadır. Bununla birlikte, kalsiyum hidroksitle uygulanan uzun apeksifikasyon tedavisi sırasında geçici restorasyonlar düşebilmekte bunun sonucunda sızıntı ve tekrarlayan enfeksiyon oluşabilmektedir. Ayrıca, Andreasen ve arkadaşları, uzun dönem kalsiyum hidroksit tedavisi uygulandığında kök gelişimi tamamlanmamış 
dişlerin fraktür direncinde anlamlı bir düşüş olduğunu rapor etmişlerdir. ${ }^{11}$ Bundan dolayı MTA ve Biodentine gibi trikalsiyum slikat içerikli materyaller biyo-uyumluluk, bakteriostatik etki ve güçlü fiziksel özelliklerin örtücülük kabiliyeti ile kombine olması nedeniyle tek seanslı apeksifikasyonda tercih edilen materyaller halini almıştır.,4-6

Biodentine, diğer kalsiyum silikat esaslı materyallerle karşılaştırıldığında büyük bir gelişme göstermiştir. MTA'nın aksine, Biodentine'nin basınç dayanımı, elastikiyet modülü ve mikro sertliği doğal dentine benzer olduğu bildirilmiştir. ${ }^{10}$ Biodentine stabil, renklenme oluşturmayan, daha az çözünen, rezorbe olmayan, hidrofilik, hazırlanması ve yerleştirilmesi kolay olan, sertleşmesi için çok daha az zamana ihtiyaç duyan, sızdırmaz bir tıkama sağlayan biyomateryaldir. ${ }^{12}$ Materyalin geliştirilmiş özellikleri nedeniyle, Biodentine açık apeksli dişlerin tedavisinde en yakın alternatiflerine göre belirgin bir avantaja sahiptir. Ayrıca Biodentine, MTA'nın 2 saat 45 dakika sertleşme süresine kıyasla 12 dakika gibi daha kısa bir sertleşme süresine sahip olması klinik olarak büyük bir avantaj sağlamaktadır. ${ }^{10,13,14}$ Biodentine'nin içeriğindeki parçacıkların daha büyük spesifik yüzey boyutuna sahip olması, sıvı faza kalsiyum klorür hızlandırıcı eklenmesi ve sıvı içeriğindeki azalmadan dolayı daha kısa sürede sertleştiği bildirilmektedir. Apeksifikasyon tedavisinde, daha hızlı sertleşme süresi MTA'da olduğu gibi iki aşamalı obtürasyon intiyacını ortadan kaldırmakta ve bakteriyel kontaminasyon riskini azaltmaktadır. ${ }^{2}$ Bu nedenlerden dolayı bu çalışmada apikal tıkaç oluşturmak amacıyla üstün fiziksel özelliklere sahip Biodentine kullanılmıştır.

Apeksifikasyon tedavisinde, kök oluşumu tamamlanmamış dişlerde kök kırılma duyarlıı̆̆ının artması ve kök kanal aletlerinin apikal genişliğin fazla olmasından dolayı kanal duvarının tamamında etkin şekillendirme sağlayamaması nedeniyle enstrumantasyon aşamasında yetersizlik oluşmaktadır. ${ }^{15} \mathrm{Bu}$ önemli klinik sınırlama nedeniyle, dezenfeksiyon antibakteriyel solüsyonların kullanımına bağlı kalmaktadır. Sodyum hipoklorit (NaOCl), pulpa dokusu üzerindeki üstün antibakteriyel ve doku çözücü özellikleri nedeniyle günümüzde en yaygın kullanılan irrigasyon maddesidir. ${ }^{16}$ Açık apeksli dişlerin apeksifikasyonunda \%2,5 ile \%6 arasında farklı konsantrasyonlarda sodyum hipaoklorit kullanılmaktadır. ${ }^{4,5,10,15,17,18}$ Sodum hipokloritin $\% 5,25$ konsantrasyonda kullanıldığı tek seans apeksifikasyon tedavilerinde uzun dönemde yüksek başarı oranları gösteren çalışmalar bildirilmiştir. ${ }^{15,17,18}$ Bu vaka raporunda da mevcut çalışmaların sonuçlarını göz önünde bulundurularak, irrigasyon uygulaması sırasında yandan perfore irrigasyon iğnesi ile apikalden $2 \mathrm{~mm}$ kısa olacak şekilde ve düşük hızda yapılan irrigasyonla apikal taşkınlık intimalini azaltacak önlemler alınarak \%5,25 sodyum hipoklorit kullanılmıştır.

Kök kanal irriganlarının, mekanik kök kanal preparasyon tekniklerinin, kök kanal dolgu materyallerinin ve kök kanal medikamentlerinin dentinin mekanik özellikleri üzerindeki etkileri, endodontik olarak tedavi edilen olgunlaşmamış dişlerin prognozunun belirlenmesinde önemli bir rol oynamaktadır. ${ }^{19}$ Kalsiyum hidroksit ile kök kanalının doldurulmasının ardından dentinin \% 23-43.9 oranında zayıflaması, olgunlaşmamış dişlerde apikal bariyer oluşturmak için bu materyalin uzun süreli kullanımına bağlanmıştır. ${ }^{20}$ Bununla birlikte, kök kanalını dezenfekte etmek için kısa süreli kalsiyum hidroksit, kök kanal dolumu öncesi endodontik medikament olarak kullanılmıştır. ${ }^{21}$ Bugüne kadar, bir ay veya daha kısa bir süre kalsiyum hidroksit uygulamasının radiküler dentinin mekanik özellikleri üzerinde olumsuz etkisi olduğuna dair kesin bir veriye rastlanmamıştır. ${ }^{22}$ Ayrıca, yapılan bir çalışmada apeksifikasyon prosedürlerinde trikalsiyum silikat içerikli materyalin ve kalsiyum hidroksitin birlikte kullanımının periodonsiyumun rejenerasyonunu olumlu yönde etkileyeceği bildirilmiştir. ${ }^{23}$ Bu vakada antimikrobiyal ve sert doku yapımını uyarı$\mathrm{Cl}$ etkisinden yararlanmak için kalsiyum hidroksit iki hafta boyunca bekletilmiştir.

Biodentine ile yapılan apeksifikasyon çalışmalarında yeterli sızdırmazlık ve mekanik özellikleri elde edebilmek için yapılan çalışmalarda 5 mm'lik bir tıkaç oluşturulmuştur. ${ }^{24}$ Bu nedenden dolayı bu çalışmada apikalde 5 mm'lik bir tıkaç oluşturulmuş ve kök kanallarının geri kalan kısmı sıcak vertikal kompaksiyon tekniği ile doldurulmuştur.

Kök oluşumunun tamamlanmadığı bazı vakalarda alternatif bir tedavi olarak apikal kapanmayı indükleyecek bir kan pıhtısı üretmek için periapikal bölgenin overinstrumentasyonu yoluyla revaskülarizasyon tedavisi uygulanmıştır. ${ }^{25}$ Her ne kadar pulpa revaskülarizasyonu bu gibi durumlar için iyi bir tedavi seçeneği olarak kalsa da hastanın yeterli zamanının olmaması ve ailesinin revaskülarizasyonu kabul etmemesi nedeniyle bu vaka için Biodentine apeksifikasyonu seçilmiştir.

3, 6 ve 12 aylık takipler sonucunda benzer çalışmalarda olduğu gibi klinik belirti ve semptomlar geçmiş, radyografik incelemelerde apikal bölgede kemik ve sement oluşumu izlenmiştir. ${ }^{4-6,12}$

\section{KAYNAKLAR}

1.Simon S, Rilliard F, Berdal A, Machtou P. The use of mineral trioxide aggregate in one-visit apexification treatment: a prospective study. Int Endod J 2007; 40: 186-197. 2.Endodontists AAo. Glossary of endodontic terms. 2019 [Ninth [Available from: http://www.aae.org/glossary.

3.Sheehy EC, Roberts GJ. Use of calcium hydroxide for apical barrier formation and healing in non-vital immature permanent teeth: a review. Br Dent J 1997; 183: 241-246. 4.Elumalai D, Kapoor B, Tewrai R, Mishra S. Comparison of mineral trioxide aggregate and Biodentine for management of open apices. J Interdiscip Dentistry 2015; 5: 131135. 
5.Martens L, Rajasekharan S, Cauwels R. Endodontic treatment of trauma-induced necrotic immature teeth using a tricalcium silicate-based bioactive cement. A report of 3 cases with 24-month follow-up. Eur J Paediatr Dent 2016; 17: 24-28.

6.Bajwa NK, Jingarwar MM, Pathak A. Single Visit Apexification Procedure of a Traumatically Injured Tooth with a Novel Bioinductive Material (Biodentine). Int J Clin Pediatr Dent 2015; 8: 58-61.

7.Parirokh $\mathrm{M}$, Torabinejad $\mathrm{M}$. Mineral trioxide aggregate: a comprehensive literature review--Part I: chemical, physical, and antibacterial properties. J Endod 2010; 36: 16-27. 8.Parirokh $\mathrm{M}$, Torabinejad $\mathrm{M}$. Mineral trioxide aggregate: a comprehensive literature review--Part III: Clinical applications, drawbacks, and mechanism of action. J Endod 2010; 36: 400-413.

9.Perard M, Le Clerc J, Watrin T, Meary F, Pérez F, et al. Spheroid model study comparing the biocompatibility of Biodentine and MTA. J Mater Sci Mater Med 2013; 24: 1527-1534.

10.Rajasekharan S, Martens LC, Cauwels RG, Verbeeck RM. Biodentine ${ }^{\mathrm{Tm}}$ material characteristics and clinical applications: a review of the literature. Eur Arch Paediatr Dent 2014; 15: 147-158.

11.Andreasen JO, Farik B, Munksgaard EC. Long-term calcium hydroxide as a root canal dressing may increase risk of root fracture. Dent Traumatol 2002; 18: 134-137.

12. Bachoo IK, Seymour D, Brunton P. Clinical case reports using a novel calcium-based cement. Br Dent J 2013; 214: 61-64.

13.Torabinejad M, Hong CU, McDonald F, Pitt Ford TR. Physical and chemical properties of a new root-end filling material. J Endod 1995; 21: 349-353.

14.Goldberg $M$, Pradelle-Plasse $N$, Tran XV, Colon P. Emerging trends in Biomaterials; VI-2-1 physico-chemical properties. Oxfordshire: Coxmoor Publishing Company; 2009.

15.Pace R, Giuliani V, Nieri M, Di Nasso L, Pagavino G. Mineral trioxide aggregate as apical plug in teeth with necrotic pulp and immature apices: a 10-year case series. J Endod 2014; 40: 1250-1254.

16. Retamozo B, Shabahang S, Johnson N, et al. Minimum contact time and concentration of sodium hypochlorite required to eliminate enterococcus faecalis. J Endod 2010; 36: 520-523.

17. Musale PK, Kothare S. Non-surgical endodontic management of immature permanent mandibular first molar: a 3 year follow-up. Eur Arch Paediatr Dent 2018; 19: 373377.

18.Witherspoon DE, Small JC, Regan JD, Nunn M. Retrospective analysis of open apex teeth obturated with mineral trioxide aggregate. J Endod 2008; 34: 1171-1176.

19.Moazami F, Sahebi S, Jamshidi D, Alavi A. The long- term effect of calcium hydroxide, calcium-enriched mixture cement and mineral trioxide aggregate on dentin strength. Iran Endod J 2014; 9: 185-189.

20.Rosenberg B, Murray PE, Namerow K. The effect of calcium hydroxide root filling on dentin fracture strength. Dent Traumatol 2007; 23: 26-29.

21.White JD, Lacefield WR, Chavers LS, Eleazer PD. The effect of three commonly used endodontic materials on the strength and hardness of root dentin. J Endod 2002; 28: 828-830.

22.Yassen $\mathrm{GH}$, Platt JA. The effect of nonsetting calcium hydroxide on root fracture and mechanical properties of radicular dentine: a systematic review. Int Endod J 2013; 46: 112-118.

23.Pace R, Giuliani V, Pini Prato L, Baccetti T, Pagavino G. Apical plug technique using mineral trioxide aggregate: results from a case series. Int Endod J 2007; 40: 478-484. 24.Vidal K, Martin G, Lozano O, Salas M, Trigueros J, Aguilar G. Apical Closure in Apexification: A Review and Case Report of Apexification Treatment of an Immature Permanent Tooth with Biodentine. J Endod 2016; 42: 730-734.

25.Thibodeau B, Trope M. Pulp revascularization of a necrotic infected immature permanent tooth: case report and review of the literature. Pediatr Dent 2007; 29: 47-50. 